\title{
OS JOVENS E O CONSUMO SOCIALMENTE RESPONSÁVEL
}

\author{
Regis Thomaz Ximenes \\ Mestre em Administração pelo Centro Universitário da FEI - FEI \\ Professor da Faculdade Drummond - DRUMMOND \\ regisximenes@gmail.com
}

\author{
Suzane Strehlau \\ Doutora em Administração de Empresas pela Fundação Getúlio Vargas - FGV/SP \\ Professora da Universidade Nove de Julho - UNINOVE \\ strehlau@gmail.com
}

\begin{abstract}
RESUMO
O objetivo deste artigo é avaliar o consumo socialmente responsável dos estudantes do ensino médio em escolas públicas de comunidades com recursos econômicos diferentes. Mais especificamente, se há diferença entre estes estudantes em duas comunidades semelhantes, sendo que uma tem como atividade econômica principal o turismo e a outra, a indústria de manufatura. A escolha por jovens está relacionada com a sua maior facilidade de aceitar as inovações e os novos hábitos, por serem alvo de programas de educação ambiental nas escolas e indicadores de mudança de comportamento para as novas gerações. O referencial teórico se apóia nos estudos de responsabilidade social corporativa e de marketing social. O levantamento foi efetuado em colégios públicos de ensino médio sorteados aleatoriamente em dois municípios. Os estudantes do ensino médio autopreencheram um questionário sobre seus hábitos de consumo, dados demográficos e uma escala mensurando o comportamento socialmente responsável do consumidor. O método de análise consistiu do uso das estatísticas descritivas, teste de qui-quadrado e teste t. Os resultados revelam que no município com base industrial mais forte, os estudantes do nível médio apresentam consumo socialmente mais responsável do que aqueles que vivem em uma cidade que depende do turismo para sua sobrevivência. A contribuição deste trabalho está na análise do impacto da atividade econômica da comunidade, em que vive o consumidor, no consumo socialmente responsável.
\end{abstract}

Palavras-chave: Comportamento; Consumidor; Jovens.

\section{THE YOUNG AND SOCIALLY RESPONSIBLE CONSUMPTION}

\begin{abstract}
The aim of this paper is to evaluate the socially responsible consumption of high school students in public schools in communities with different economic resources. More specifically, the research intends to define if there are differences between these students in two similar communities, one that has its major economic activity in the tourism industry and the other in the manufacturing area. The choice for young people is related to their ease of accepting innovations and new habits. Also, the students are the target of environmental education programs in schools and are indicators of behavior change for future generations. The theoretical framework is based on studies of corporate social responsibility and social marketing. The survey was conducted in public high schools randomly selected from two counties. The high school students filled in a questionnaire about their drinking habits, demographics, and a scale measuring socially responsible consumer behavior. The analysis method consisted of the use of descriptive statistics, chi-square and tests. The results reveal that in the city with the strongest industrial base, high school students present as more socially responsible in consumption than those who live in a city that depends on tourism for its survival. The contribution of this paper is to analyze the impact of economic activity on responsible consumption in the community in which the consumers live.
\end{abstract}

KeyWords: Consumer Behavior; Corporate Social Responsibility; Social Marketing.

* Apoio recebido do Fundo de Apoio a Pesquisa - FAP/UNINOVE. 


\section{INTRODUÇÃO}

As iniciativas de marketing social são apontadas no modelo conceitual, elaborado por Bloom e Gundlach (2001), como objeto de estudo das relações do marketing com a sociedade. Uma das contribuições do marketing para o sistema econômico é a perspectiva ampla de benefícios derivada, em parte, da pressão constante por melhorias e inovações. Uma destas forças é a responsabilidade com o meio ambiente. Muito se estudou o comportamento do consumidor em relação à alguma marca específica ou produto, mas pouco sobre o seu padrão de ação no seu cotidiano.

Este artigo teórico e empírico tem como objetivo geral avaliar o consumo socialmente responsável dos estudantes do ensino médio em escolas públicas de comunidades com recursos econômicos diferentes. Mais especificamente, busca-se saber se há diferença na preocupação com o consumo socialmente responsável entre os estudantes de ensino médio de duas comunidades semelhantes, sendo que uma tem como sua principal atividade econômica o turismo, enquanto a outra se baseia na indústria de manufatura.

A escolha por jovens está relacionada com a sua maior facilidade de aceitar as inovações e em assimilar novos hábitos, além de serem alvo de programas de educação ambiental nas escolas. Há dúvidas em relação a possíveis interpretações quanto a definir um único perfil para os jovens da atualidade, mesmo assim os resultados dão viés do comportamento e da visão de mundo da juventude contemporânea (Instituto Akatu, 2002). Os estudantes são residentes em duas cidades semelhantes, porém com relações diferentes quanto à dependência da natureza à sua volta. As cidades de Jaguariúna e Ilhabela foram selecionadas para a pesquisa de campo, os motivos da escolha estão detalhados nos procedimentos metodológicos.

\section{REFERENCIAL TEÓRICO}

O desenvolvimento sustentável propõe a conciliação entre desenvolvimento socioeconômico, gerando riquezas, conforto, emprego, saúde etc, aliado conjuntamente ao comportamento ambientalmente correto. O consumidor socialmente responsável é definido como aquele que considera as consequências públicas do seu consumo privado e que acredita que com o seu poder de compra poderá promover uma modificação social. (Webster, 1975). Anderson Jr. e Cunningham (1972) procuraram caracterizar quem seriam estes consumidores e buscaram descrevêlos nas variáveis demográficas e sociopsicológicas. Houve debate acirrado entre formas de mensurar e como seria o perfil do consumidor com maior nível de consciência de responsabilidade social no consumo entre Webster e Cunningham, e recomendou-se que, no longo termo, os pesquisadores explorassem as condições sob as quais a consciência social se expressaria em comportamento de consumo (Mayer, 1976).

Resultado de estudo conduzido nos Estados Unidos por Mohr et al (2001) mostrou que a maioria dos consumidores não usa a responsabilidade social corporativa como critério de compra. Embora estejam pouco comprometidos, quase todos já realizaram pelo menos uma compra na qual a decisão foi tomada de acordo com estes critérios.

O consumidor age como um stakeholder que exibe preferências de marca em decorrência de ações de responsabilidade social corporativa. Por exemplo, Mrtvi (2003) descreve os efeitos, do ponto de vista do consumidor, nas marcas de empresas de cosméticos com ações de responsabilidade social (projetos sociais ou ambientais). Todavia, os hábitos de consumo estão mais baseados na preocupação econômica do que ecológica (Jöhr, 1994). Mas por outro lado, aparentemente, as práticas de responsabilidade social ambiental das empresas estão sendo mais valorizadas. Diversas pesquisas relacionadas ao tema sobre o comportamento do consumidor explicam que só $15 \%$ dos consumidores no Brasil não compram de quem prejudica o ambiente, contra 51\% na Austrália e $42 \%$ nos EUA e na Alemanha. 
Magalhães e Damacena (2006) afirmaram que as pesquisas discordam do que se podem considerar como variáveis moderadas mais relevantes entre a responsabilidade social corporativa (RSC) e a intenção de compra. Em suma, características psicológicas e demográficas dos consumidores, geralmente, estão associadas aos diversos fatores que influenciam o consumidor, mas pouco se explorou a relação entre consumidores que moram em cidades que têm relação econômica diferente com o meio ambiente.

As narrativas dos jovens sobre o consumo ambientalmente correto refletem os recursos culturais e o contexto formado pelo material educacional utilizado nas escolas e as campanhas publicitárias. A interpretação deste material pelos estudantes foi objeto de uma pesquisa qualitativa por Autio, Heiskanen e Heinonen (2009) e os resultados gerados mostram três posições diferentes herói, anti-herói, anarquista. O Herói representa o discurso dominante, no qual o consumidor é bem informado e racional. Já o anti-herói emerge da rejeição das hipóteses simplificadas e prescrições do discurso dominante, este jovem usa de ironia e do fatalismo; ao passo que o anarquista está fora do discurso dominante, e a proposta é que se alguém quiser tomar o ambiente e justiça social a sério, é preciso ir além do papel de um consumidor responsável, agindo de acordo com a comunicação na mídia. Mais interessante, porém é o que os autores revelam em comum entre estes perfis: que todas as histórias sobre o consumo verde não são atraentes ou da moda, exceto se ganhar prazer na negação da cultura de consumo.

\section{MÉTODO DE PESQUISA}

A proposta aqui é estudar aspectos do consumo socialmente responsável do consumidor, analisando o impacto da variável dependência econômica da comunidade em relação à natureza ao seu redor. Um levantamento foi feito por meio de um questionário, estruturado com perguntas fechadas e autopreenchido. Os respondentes foram estudantes de escolas públicas que estavam cursando o ensino médio e que, obrigatoriamente, eram residentes em uma das duas cidades.

O universo da pesquisa foi constituído pelas escolas públicas de ensino médio situadas nas cidades de Jaguariúna e Ilhabela, no Estado de São Paulo. A amostra é probabilística aleatória simples, um número foi atribuído para cada elemento da população (escolas públicas de ensino médio em cada cidade selecionada) e fez-se a seleção aleatória por meio de um sorteio. Das três escolas públicas estaduais existentes de ensino médio na cidade de Jaguariúna, a sorteada foi a E.E. Professor Anna Calvo de Godoy e das cinco escolas públicas estaduais existentes de ensino médio na cidade de Ilhabela, a escolhida foi a E.E. Professor Gabriel Ribeiro dos Santos. Os pesquisadores entraram em contato com as diretoras das escolas que permitiram a coleta de dados.

De posse dos questionários, a primeira etapa foi analisar a homogeneidade da variância nas questões separadamente por meio da estatística qui-quadrado. Em seguida, as respostas de cada respondente foram somadas, calculou-se a média por cidade e testou-se a diferença entre as médias de cada cidade.

\subsection{Seleção das cidades}

Os critérios para a escolha das cidades foram o tamanho da população, localização próxima à Capital, ter como principal fonte de riqueza do município uma atividade dependente do meio ambiente (como turismo) e outra dependente somente de indústrias de manufatura. Inicialmente foram selecionadas algumas cidades litorâneas do Estado de São Paulo com forte dependência econômica do turismo e, em seguida, procurou-se identificar, de acordo com os critérios estabelecidos previamente, uma cidade com características semelhantes que fosse diferente quanto à principal atividade econômica.

Uma das cidades escolhidas foi Jaguariúna, situada no interior do Estado de São Paulo, com uma população de residentes em expansão de 29.597 habitantes em 2001 para 36.804 em 2007. 
Com uma base territorial de $142 \mathrm{~km}^{2}$, possui nove agências bancárias e treze estabelecimentos de saúde, sendo que oito pertencem ao estabelecimento de saúde SUS. Possui cinco escolas de ensino médio, sendo três escolas públicas estaduais e duas escolas particulares. No ano de 2007, foram matriculados nas escolas públicas 1517 alunos e 232 alunos fizeram suas matrículas nas escolas privadas de ensino médio. Seu pólo industrial é composto de 14 indústrias extrativas e 224 indústrias de transformação, destacando-se no cenário nacional e internacional. Seu parque industrial congrega empresas que atuam em vários setores da economia: bebidas, informática, comunicações, medicamentos, cerâmica, metalurgia, autopeças, avicultura etc, alcançando um PIP (2005), a preço de mercado corrente, no valor de R\$3.045.284 (www.ibge.com.br acesso em 26/03/2008). Jaguariúna apresenta uma infraestrutura moderna, com boa sinalização de trânsito, avenidas principais com rotatórias e ausência de semáforos. Não há concentração exagerada de bairros superaglomerados.

A outra comunidade escolhida, chamada Ilhabela, está localizada no litoral norte de São Paulo, com uma população residente de 20.836 habitantes em 2001 e 23.886 no ano de 2007. Possui uma base territorial de $348 \mathrm{~km}^{2}$ com cinco agências bancárias e onze estabelecimentos de saúde SUS. Possui oito escolas de ensino médio, sendo cinco delas escolas públicas estaduais e três particulares. No ano de 2007, foram matriculados nas escolas públicas 1008 alunos e 105 alunos fizeram suas matrículas nas escolas privadas de ensino médio. Sua economia está focada no turismo, sendo seu produto principal a natureza preservada. Não possui indústrias extrativas e apenas 32 indústrias de transformação, sendo que seu PIP (2005), a preço de mercado corrente, alcançou o valor de R\$ 187.099. É classificada como estância turística, tendo como vocação o turismo. Do seu território total, $80 \%$ faz parte dos parques estaduais da Serra do Mar e de Ilhabela e os $20 \%$ restantes estão, em sua maioria, com demarcações de áreas de preservação permanente, como mangues, restingas e beiras de rio. O espaço físico disponível para ocupação humana é limitado e seus habitantes vivem numa pequena parte dos seus 348 quilômetros quadrados. As famosas belezas naturais estão sendo prejudicadas pelo crescimento de favelas, desmatamento e crescimento desordenado, causando poluição do solo e água. (www.ibge.com.br acesso em 26/03/2008)

\subsection{Escala comportamento de consumo socialmente responsável (CCSR)}

O construto consumo socialmente responsável foi definido como o nível de preocupação quanto ao comportamento dos consumidores e suas decisões de compra que estão relacionadas a questões ambientais e recursos naturais, bem como a preservação do meio ambiente e a preocupação com o bem-estar da sociedade para as futuras gerações. A operacionalização deste conceito foi concretizada por meio da escala desenvolvida por Antil e Bennet (1979), "Comportamento de Consumo Socialmente Responsável" (SRCB), composta por 40 afirmações com escala do tipo Likert. (Antil e Bennett, 1979 apud Bearden e Netemeyer, 1999).

A escala foi traduzida para o português e discutida com especialistas em marketing. Logo após, houve um pré-teste com 213 estudantes universitários, por meio de uma amostra nãoprobabilística por acessibilidade (Vergara, 2004). Esta forma é considerada apropriada, pois elege os elementos pela sua facilidade de acesso. O resultado do pré-teste indicou um aprimoramento na tradução de alguns itens da escala e boa validade interna com Alfa de Cronbach $=0,816$. Hair (2006, p. 90) considera valores de 0,60 a 0,70 como o limite inferior de aceitabilidade.

As alterações nas questões 1, 2, 20 (apresentadas no próximo item) foram de ordem para melhorar a compreensão. Na questão 1 acrescentou-se as palavras "poluição sonora" e na número dois substituiu-se "parar de aumentar" para "diminuir o consumo". Na vigésima, o original era "Provavelmente doaria um dia de salário para uma fundação que ajudasse a melhorar o meio ambiente" como estudantes não tinham trabalho remunerado, optou-se por reescrever " Se estivesse trabalhando, provavelmente, doaria um dia de salário para uma fundação que ajudasse a melhorar o meio ambiente". 
Outras alterações foram nas questões 27 e 33 que forneciam valores. Na questão 27, retirouse a porcentagem dos impostos "Eu estaria disposto a aceitar e pagar um aumento de 5\% nos impostos [...] e na de número 33, retirou-se o valor das despesas da família "Eu estaria disposto a aceitar um aumento nas despesas totais da minha família de $\mathrm{R} \$ 120$ no próximo ano [...]

\section{ANÁLISE DOS RESULTADOS}

Foram coletados 281 questionários, conforme se observa na tabela 1, sendo 143 respondentes $(50,9 \%)$ oriundos de Ilhabela e 138 de Jaguariúna $(49,1 \%)$. O gênero feminino representa 50,9\%, com 143 representantes e 138 homens.

Tabela 1 - Descrição da amostra Local X Gênero

\begin{tabular}{|c|c|c|c|}
\hline & \multicolumn{2}{|c|}{ Local } & Total \\
\hline Gênero & Ilhabela & Jaguariúna & \\
\hline Masculino & 69 & 69 & 138 \\
\hline Feminino & 74 & 69 & 143 \\
\hline Total & 143 & 138 & 281 \\
\hline$\%$ Total & 50,89 & 49,11 & 100 \\
\hline
\end{tabular}

Fonte: Pesquisa de campo

Para analisar as semelhanças e diferenças nos padrões de respostas dos jovens das duas cidades, foi feito o teste de homogeneidade, utilizando a estatística qui-quadrado. Utilizou-se um nível de significância de 5\% para rejeição da hipótese nula, ou seja, rejeitou-se que os respondentes dos dois grupos tivessem o mesmo padrão de resposta quando o resultado do p-valor se apresentou inferior a 0,05 , e não se rejeitou quando ele foi superior.

Ao todo, 13 questões apresentaram diferenças estatísticas nos padrões de respostas dos jovens das duas cidades. O resultado é apresentado na Tabela 2, que contém, inicialmente, a pergunta utilizada no questionário, em seguida, o resultado do teste de homogeneidade (quiquadrado e p-valor) e, finalmente, se a hipótese de homogeneidade, no padrão de resposta entre os respondentes das duas cidades, foi rejeitada ou não.

Tabela 2: Qui-quadrado dos itens da escala Antil e Bennet (1979)

\begin{tabular}{|l|c|c|c|}
\hline \multicolumn{1}{|c|}{ Variável } & $\chi \mathbf{2}$ & $\begin{array}{c}\text { P- } \\
\text { valor }\end{array}$ & Hipóteses \\
\hline $\begin{array}{l}\text { 1. As pessoas deveriam estar mais preocupadas em reduzir ou } \\
\text { limitar o ruído em nossa sociedade. }\end{array}$ & 6,051 & 0,195 & Não Rejeitado \\
\hline $\begin{array}{l}\text { 2. As pessoas devem diminuir o consumo de produtos, de modo } \\
\text { que os recursos naturais possam durar mais tempo. }\end{array}$ & 7,553 & 0,109 & Não Rejeitado \\
\hline $\begin{array}{l}\text { 3. Para o consumidor moderno, os benefícios dos produtos são } \\
\text { mais importantes do que a poluição que resulta da sua produção e } \\
\text { utilização (r). }\end{array}$ & 22,207 & 0,000 & Rejeitado \\
\hline $\begin{array}{l}\text { 4. A poluição é, atualmente, um dos problemas mais críticos de } \\
\text { nosso país. }\end{array}$ & 7,801 & 0,099 & Não Rejeitado \\
\hline $\begin{array}{l}\text { 5. Não me parece que estamos fazendo o suficiente para } \\
\text { incentivar os produtores a utilizar embalagens recicláveis. }\end{array}$ & 7,190 & 0,126 & Não Rejeitado \\
\hline $\begin{array}{l}\text { 6. Penso que não estamos fazendo o suficiente para salvar os } \\
\text { recursos naturais escassos de serem utilizados. }\end{array}$ & 9,089 & 0,059 & Não Rejeitado \\
\hline $\begin{array}{l}\text { 7. Os recursos naturais devem ser preservados, mesmo que as } \\
\text { pessoas tenham de deixar de utilizar alguns produtos. }\end{array}$ & 12,993 & 0,011 & Rejeitado \\
\hline
\end{tabular}

Revista de Gestão Social e Ambiental - RGSA, São Paulo, v. 6, n. 2, p. 180-189, maio/ago. 2012. 


\begin{tabular}{|c|c|c|c|}
\hline Variável & $\chi^{2}$ & $\begin{array}{c}\text { P- } \\
\text { valor }\end{array}$ & Hipóteses \\
\hline $\begin{array}{l}\text { 8. Todos os consumidores devem estar interessados nas } \\
\text { consequências ambientais dos produtos que compram }\end{array}$ & 2,651 & 0,618 & Não Rejeitado \\
\hline 9. A poluição não está particularmente afetando minha vida (r) & 6,201 & 0,185 & Não Rejeitado \\
\hline $\begin{array}{l}\text { 10. Os consumidores devem ser obrigados a pagar preços mais } \\
\text { elevados para os produtos que poluem o meio ambiente }(\mathrm{r})\end{array}$ & 10,385 & 0,034 & Rejeitado \\
\hline $\begin{array}{l}\text { 11. Eu realmente fico indignado em pensar que o governo não } \\
\text { está fazendo mais para ajudar a controlar a poluição do meio } \\
\text { ambiente. }\end{array}$ & 4,642 & 0,326 & Não Rejeitado \\
\hline $\begin{array}{l}\text { 12. Garrafas, latas ou outros produtos que não possam ser } \\
\text { reciclados, deveriam ser proibidos por lei sua devolução ao meio } \\
\text { ambiente. }\end{array}$ & 11,873 & 0,018 & Rejeitado \\
\hline $\begin{array}{l}\text { 13. Eu estaria disposto a assinar uma petição, abaixo-assinados } \\
\text { ou iniciar ações por uma causa ambiental. }\end{array}$ & 8,617 & 0,071 & Não Rejeitado \\
\hline $\begin{array}{l}\text { 14. Às vezes, penso que se pudéssemos consumir um pouco } \\
\text { menos, haveria mais para as gerações futuras. }\end{array}$ & 9,318 & 0,054 & Não Rejeitado \\
\hline $\begin{array}{l}\text { 15. O Governo Federal deve subsidiar pesquisas sobre } \\
\text { tecnologias de reciclagem de produtos e resíduos. }\end{array}$ & 11,546 & 0,021 & Rejeitado \\
\hline $\begin{array}{l}\text { 16. Eu estou disposto a ir para o trabalho de bicicleta ou a pé, a } \\
\text { fim de reduzir a poluição do ar. }\end{array}$ & 16,491 & 0,002 & Rejeitado \\
\hline $\begin{array}{l}\text { 17. Eu, provavelmente, nunca vou participar de um grupo ou } \\
\text { clube que está preocupado apenas com questões ecológicas (r). }\end{array}$ & 5,252 & 0,262 & Não Rejeitado \\
\hline $\begin{array}{l}\text { 18. Eu sinto que as pessoas estão muito preocupadas com a } \\
\text { existência de pesticidas em produtos alimentares (r). }\end{array}$ & 12,572 & 0,014 & Rejeitado \\
\hline $\begin{array}{l}\text { 19. Esta questão da poluição nunca me preocupou, pois sinto que } \\
\text { há muito exagero nela (r). }\end{array}$ & 13,934 & 0,008 & Rejeitado \\
\hline $\begin{array}{l}\text { 20. Se estivesse trabalhando, provavelmente, doaria um dia de } \\
\text { salário para uma fundação que ajudasse a melhorar o meio } \\
\text { ambiente. }\end{array}$ & 6,009 & 0,198 & Não Rejeitado \\
\hline $\begin{array}{l}\text { 21. Eu estaria disposto a ter minha roupa menos branca ou macia } \\
\text { em troca da certeza de que estaria usando um produto não } \\
\text { poluente na sua lavagem. }\end{array}$ & 12,82 & 0,012 & Rejeitado \\
\hline $\begin{array}{l}\text { 22. Os fabricantes devem ser obrigados a utilizar materiais } \\
\text { reciclados na fabricação de produtos e nos processos } \\
\text { operacionais. }\end{array}$ & 11,759 & 0,019 & Rejeitado \\
\hline $\begin{array}{l}\text { 23. Acho que as pessoas deveriam conversar com seus amigos } \\
\text { para não utilizarem produtos que poluam ou prejudiquem o } \\
\text { ambiente. }\end{array}$ & 7,579 & 0,108 & Não Rejeitado \\
\hline $\begin{array}{l}\text { 24. Propagandas e comerciais devem ser obrigados a mencionar } \\
\text { as desvantagens ecológicas dos produtos. }\end{array}$ & 9,358 & 0,053 & Não Rejeitado \\
\hline $\begin{array}{l}25 \text { Estão dando importância demais para esta questão da poluição } \\
\text { do ar e da água do que é realmente para ser dado(r). }\end{array}$ & 9,410 & 0,052 & Não Rejeitado \\
\hline $\begin{array}{l}\text { 26. O governo deve fornecer para cada cidadão uma lista de } \\
\text { agências e organizações, a fim de que os cidadãos possam } \\
\text { informar e registrar queixas relativas à poluição. }\end{array}$ & 4,116 & 0,391 & Não Rejeitado \\
\hline $\begin{array}{l}\text { 27. Eu estaria disposto a aceitar e pagar um aumento nos } \\
\text { impostos para que o governo desse maior apoio no controle da } \\
\text { poluição. }\end{array}$ & 1,125 & 0,890 & Não Rejeitado \\
\hline $\begin{array}{l}\text { 28. Tentar controlar a poluição das águas gera mais problemas do } \\
\text { que benefícios (r). }\end{array}$ & 4,547 & 0,337 & Não Rejeitado \\
\hline $\begin{array}{l}\text { 29. Eu fico indignado quando penso sobre o prejuízo que a } \\
\text { poluição está fazendo à vida vegetal e animal. }\end{array}$ & 9,084 & 0,059 & Não Rejeitado \\
\hline
\end{tabular}




\begin{tabular}{|l|c|c|c|}
\hline \multicolumn{1}{|c|}{ Variável } & $\boldsymbol{1} \mathbf{2}$ & $\begin{array}{c}\text { P- } \\
\text { valor }\end{array}$ & Hipóteses \\
\hline $\begin{array}{l}\text { 30. As pessoas deveriam tentar convencer seus amigos a limitar o } \\
\text { uso de produtos feitos a partir de recursos escassos. }\end{array}$ & 6,974 & 0,137 & Não Rejeitado \\
\hline $\begin{array}{l}\text { 31. Eu estaria disposto a pagar mais um "real" a cada mês para a } \\
\text { produção de eletricidade, se significar um ar mais limpo. }\end{array}$ & 9,228 & 0,056 & Não Rejeitado \\
\hline $\begin{array}{l}\text { 32. Seria sensato o Governo aplicar mais recursos para apoiar um } \\
\text { amplo programa de conservação ambiental. }\end{array}$ & 2,032 & 0,730 & Não Rejeitado \\
\hline $\begin{array}{l}\text { 33. Eu estaria disposto a aceitar um aumento nas despesas totais } \\
\text { da minha família para o próximo ano com o intuito de promover } \\
\text { a utilização racional dos recursos naturais. }\end{array}$ & 2,610 & 0,625 & Não Rejeitado \\
\hline $\begin{array}{l}\text { 34. Produtos que, na sua fabricação ou utilização, poluírem o } \\
\text { ambiente devem ter altos impostos cobrados pelo governo. }\end{array}$ & 15,860 & 0,003 & Rejeitado \\
\hline $\begin{array}{l}\text { 35. As pessoas devem estar dispostas a aceitar fumaça (poluição) } \\
\text { em troca da comodidade dos automóveis (r). }\end{array}$ & 9,085 & 0,059 & Não Rejeitado \\
\hline $\begin{array}{l}\text { 36. Quando penso nas formas que algumas indústrias poluem, } \\
\text { fico frustrado e indignado. }\end{array}$ & 8,481 & 0,075 & Não Rejeitado \\
\hline $\begin{array}{l}\text { 37. Nossas escolas públicas e particulares devem exigir que todos } \\
\text { os estudantes façam um curso sobre como lidar com os } \\
\text { problemas ambientais e de conservação. }\end{array}$ & 4,561 & 0,335 & Não Rejeitado \\
\hline $\begin{array}{l}\text { 38. Eu estaria disposto a deixar de comprar produtos de empresas } \\
\text { responsáveis de poluir o meio ambiente, embora isso possa ser } \\
\text { inconveniente para minha família. }\end{array}$ & 23,042 & 0,000 & Rejeitado \\
\hline $\begin{array}{l}\text { 39. Eu estaria disposto a fazer sacrifícios pessoais para defender a } \\
\text { redução da poluição, mesmo que os resultados possam não } \\
\text { parecer significativos de imediato. }\end{array}$ & 17,573 & 0,001 & Rejeitado \\
\hline $\begin{array}{l}\text { 40. Eu raramente me preocupo com os efeitos da fumaça } \\
\text { (poluição) sobre mim e minha família. }\end{array}$ & 3,480 & 0,481 & Não Rejeitado \\
\hline
\end{tabular}

\section{Fonte: Pesquisa de campo}

Nas afirmações em que se encontrou diferença nos padrões de resposta entre as duas populações, nota-se que em Jaguariúna o grau de preocupação com o bem-estar da sociedade é maior. As questões em que houve semelhança nos padrões de resposta dos dois grupos afirmavam que os benefícios dos produtos são mais importantes do que a poluição resultante; que deixariam de usar alguns produtos; que garrafas e afins não devem ser devolvidas ao meio ambiente; que o governo deve subsidiar tecnologias de reciclagem; que iriam ao trabalho à pé; que as pessoas estão muito preocupadas com a existência de pesticidas em alimentos; que não há exagero quando se fala de poluição; que material reciclado deve ser utilizado na produção; que estariam dispostos a fazer sacrifícios e que produtos poluidores devem ter mais impostos.

Um exemplo de questão com padrão diferente de resposta foi que em Ilhabela, em que os estudantes discordaram mais que os de Jaguariúna que estariam dispostos a ter sua roupa menos branca ou macia em troca da certeza de que estariam usando um produto não poluente na sua lavagem e que deveriam pagar preços mais elevados para os produtos que poluem o meio ambiente.

Finalmente, utilizando-se uma escala somada para as 40 questões (respeitando-se as questões inversas), aplicou-se o teste t para amostras independentes. A média dos 143 respondentes de Ilhabela foi 126,80 (desvio-padrão 14,9944, média do erro padrão 1,0254) e os 138 oriundos de Jaguariúna, com média 134,13 (desvio-padrão 12,531, média do erro padrão 1,067) 
Tabela 3 - Teste de Levene e Teste T de médias

\begin{tabular}{|c|c|c|c|c|c|c|c|c|c|}
\hline & \multicolumn{2}{|c|}{$\begin{array}{l}\text { Teste Levene } \\
\text { Variança da } \\
\text { amostra }\end{array}$} & \multirow[b]{2}{*}{$\mathrm{t}$} & \multirow[b]{2}{*}{$\mathrm{gl}$} & \multirow[b]{2}{*}{$\begin{array}{l}\text { Sig. } \\
(2- \\
\text { tailed }) \\
\end{array}$} & \multirow[b]{2}{*}{$\begin{array}{l}\text { Diferença } \\
\text { média }\end{array}$} & \multirow[b]{2}{*}{$\begin{array}{c}\text { Diferença } \\
\text { erro padrão }\end{array}$} & \multicolumn{2}{|c|}{$\begin{array}{c}\text { Intervalo de } \\
\text { confiança } 95 \% \text { da } \\
\text { diferença }\end{array}$} \\
\hline & $\mathrm{F}$ & Sig. & & & & & & Baixa & Alta \\
\hline $\begin{array}{l}\text { Equal } \\
\text { variances } \\
\text { assumed } \\
\end{array}$ & 5,5042 & 0,0197 & $-4,4403$ & 279 & 0,00 & $-7,3332$ & 1,6515 & $-10,5843$ & $-4,0822$ \\
\hline $\begin{array}{l}\text { Equal } \\
\text { variances not } \\
\text { assumed }\end{array}$ & & & $-4,4544$ & 273,4488 & 0,00 & $-7,3332$ & 1,6463 & $-10,5743$ & $-4,0922$ \\
\hline
\end{tabular}

Fonte:Pesquisa de campo

O teste de Levene com $\mathrm{F}=5,5042$ com 0,0197 de significância mostra que a igualdade entre as variâncias não pode ser assumida. Portanto, há diferença entre o desvio-padrão da cidade de Jaguariúna e de Ilhabela. Já o teste t com significância de 0,00 indica que existe diferença entre as médias dos dois grupos. Com $95 \%$ de confiança, pode-se afirmar que existe diferença significativa entre as médias dos dois grupos. Portanto, a cidade de Ilhabela, com média de 126,80, pontua menos na escala de comportamento de consumo socialmente responsável do que Jaguariúna, com média de 134,13. A conclusão é que os jovens de ensino médio de Ilhabela apresentam consumo socialmente consciente menor do que os jovens de Jaguariúna.

\section{CONSIDERAÇÕES FINAIS}

As relações do marketing com a sociedade talvez sejam diferentes em cidades onde há maior quantidade de empresas de manufatura. As respostas dos estudantes de Jaguariúna mostraram que são mais conscientes em relação ao consumo em comparação com os estudantes de Ilhabela, a tal ponto de darem uma pontuação alta em itens que envolvem sacrifícios pessoais, como ir ao trabalho de bicicleta ou deixar de consumir produtos que possam ajudar na sustentabilidade da sociedade. Diversas ações implementadas e praticadas na cidade de Jaguariúna recebem constantemente influências das crenças e filosofias de empresas multinacionais instaladas na região. Esse fato deverá ser estudado mais profundamente no futuro.

Os estudantes da amostra de Ilhabela, apesar de ser estância turística e sua prefeitura apresentar diversas ações de conservação ao meio ambiente, tiveram menor pontuação na escala de consumo socialmente responsável. Embora sua sobrevivência, em termos econômicos como estância turística, seja mais sensível às alterações no meio ambiente, os estudantes são menos sensíveis a este assunto.

Considerando o modelo de Carroll (1979), a sugestão é incorporar medidas relacionadas à performance social que abordem a atividade econômica das comunidades, pois é possível que esta variável impacte no comportamento dos stakeholders.

Seguindo as recomendações de Mayer (1976), procurou-se por condições sob as quais a expressão dos valores do comportamento socialmente responsável poderia variar. Os resultados obtidos indicam que a atividade econômica influencia, embora não da forma como se esperava. Acreditava-se que uma comunidade que tivesse seu sustento apoiado nos recursos naturais apresentasse maior pontuação na escala somada do que uma cidade basicamente industrial. A 
hipótese é que a cultura de qualidade, disseminada pelas empresas de manufatura, contribua com a educação para consumo socialmente responsável.

Este estudo pesquisou somente estudantes do ensino médio e, portanto, seus resultados não devem ser extrapolados para a comunidade como um todo. Sugestão para continuidade do estudo é verificar se outras cidades, com históricos e com percurso econômicos diferentes, apresentariam diferenças semelhantes àquelas apresentadas por este estudo, além disto, seria interessante comparar adultos com jovens. Como sugestão para políticas públicas, sugere-se um tratamento em termos de consumo socialmente responsável em comunidades turísticas.

\section{REFERÊNCIAS}

Antil, J.H., Bennett, P.D. (1979) Construction and validation of a scale to measure socially responsible consumption behaviour, p.51-68. In: Henion, K.E.; Kinnear, T.C. (Eds), The Conserver Society, American Marketing Association, Chicago, IL.

Anderson W. Thomas, Jr., Cunningham, William H. (Jul.1972) The socially conscious consumer The Journal of Marketing, 36(3), 23-31.

Autio, M., Heiskanen, E., Heinonen, V. (2009). Narratives of 'green' consumers - the antihero, the environmental hero and the anarchist . Journal of Consumer Behaviour, 8, pp. 40-53.

Bearden, William O., Netemeyer, Richard. (1999) Handbook of Marketing Scales. Multi-item measures for marketing and consumer behavior research. ( $2^{\text {nd }}$ ed.) Thousand Oaks, CA: Sage.

Bloom, Paul; Gundlach, Gregory (eds.) (2001) Handbook of marketing and society. Thousand Oaks, CA: Sage.

Carroll, Archie B. (oct.1979) A Three-dimensional conceptual model of corporate performance. The Academy of Management Review, 4(4), 497-505.

Instituto Akatu (2002) Os jovens e o costume sustentável. Construindo o próprio futuro? Relatório de pesquisa AKATU. São Paulo.

Jöhr, H. (1994) O verde é Negócio. São Paulo: Saraiva.

Laroche, M., Bergeron, J., Barbaro, Forteo G. , (2001) Targeting consumes who are willing to pay more for environmental friendly products. The Journal of Consumer Marketing, 18(6), 503-520.

Mayer, R.N. (set.1976) The socially conscious consumer-another look at the data. The Journal of Consumer Research, 3(2), 113-115.

Mohr, L.A., Webb, D.J., Harris, K.E. (2001) Do consumers expect companies to be socially responsible? the impact of corporate social responsibility on buying behavior. Journal of Consumer Affairs, 35(1), 45- 72.

Mrtvi, V. de O. (2003) Percepção do consumidor sobre ações corporativas vinculadas ao conceito de responsabilidade social: um estudo no setor de cosméticos. In: Enanpad, 27, Anais... Atibaia. (1 CD-ROM). 
Webster Jr, F.E. (1975) Determining the characteristics of the socially conscious consumer. The Journal of Consumer Research, 2(3), 188-195.

Data do recebimento do artigo: 13/02/2012

Data do aceite de publicação: 03/08/2012 